3 levels (cranial, middle and caudal) with grade 1 representing $1-5 \%$ emphysema, $2=6-25 \%$ emphysema, $3=26-50 \%$, $4=51-75 \%$ and $5>75 \%$ emphysema. Mean age at presentation was 40.7 (SD 5.4) years with all subjects aged 50 years or younger and 18/41 (44\%) were younger than 40 years. Mean pack years cigarette smoking was 27 (19) and subjects had smoked heroin for 14.8 (6.6) years. Mean pre-bronchodilator FEV1 was 0.99 (0.52) L; 29.9 (17.6)\%predicted and FEV1/FVC was $0.36(0.13)$. Nine subjects had moderate (GOLD stage II), 7 severe (GOLD stage III) and 25 had very severe (GOLD stage IV) COPD. DLco was 41 (23)\%predicted in the 9 subjects and alpha-1-antitrypsin level was normal in the 20 subjects who had it measured. Twenty nine CT scans were high resolution and suitable for detailed analysis. 28/29 (97\%) subjects had at least grade 1 upper lobe emphysema and mean upper lobe emphysema extent (average of the 2 upper lobe scores) was 3.0 (1.4) with 15/29 (52\%) subjects having grade 3 emphysema or worse. Overall emphysema extent (average of all 6 scores) was 2.5 (1.1). Moderate bronchiectasis was seen on only 3 scans and no subject had severe bronchiectasis. The other 12 CT scans could not be precisely graded but all had been reported as showing emphysema ( 2 mild, 2 moderate, 1 moderate to severe and 7 severe). Heroin smoking is associated with very early onset severe COPD with predominant emphysema. This is an important public health message needing dissemination to heroin smokers, drug service workers and healthcare professionals.

\section{P126 THE PREVALENCE OF SELF REPORTED RESPIRATORY SYMPTOMS AND DIAGNOSES AMONGST PATIENTS ATTENDING A DRUG DEPENDANCE CLINIC}

${ }^{1} \mathrm{~A}$ Tridimas, ${ }^{1} \mathrm{~T}$ Archer, ${ }^{1} \mathrm{Z}$ Rehman, ${ }^{2} \mathrm{~S}$ Oelbaum, ${ }^{1} \mathrm{H}$ Burhan; ${ }^{1}$ Royal Liverpool University Hospital, Liverpool, United Kingdom; ${ }^{2}$ Addaction, Liverpool, United Kingdom

\subsection{6/thoraxjn-2013-204457.276}

Introduction In England it is estimated that between the ages of $15-64,2.2 \%$ use cocaine, $6.8 \%$ use cannabis and $0.8 \%$ use opiates on a regular basis ${ }^{1}$. Illicit drug use such as crack cocaine smoking, heroin smoking and intravenous heroin also contribute to a range of respiratory conditions. A significant proportion of drug users also smoke tobacco. For a wide range of social, psychological and economic reasons, respiratory conditions within this population may often go undiagnosed for many years. Often their disease can progress to become severe before any medical input is sought. Aim: To ascertain a detailed tobacco and nontobacco smoking history and the prevalence of respiratory symptoms, prior diagnostic investigations and diagnoses amongst clients in the criminal justice system attending an inner city drug treatment clinic run by Addaction.

Methods Questionnaires were administered by Addaction staff and junior doctors from the respiratory department as part of a service evaluation. In order to ascertain whether their symptoms were likely to represent underlying COPD, a validated questionnaire was used ${ }^{5}$. The definitive diagnostic test for COPD is spirometryhowever in this particular group of people this is difficult to obtain due to frequently chaotic lifestyles.

Results A total of 62 clients completed questionnaires. 44 (71\%) smoked cigarettes, 39 (63\%) tobacco (mean pack years (SD) combined cigarettes/tobacco 23.5 (25)), 40 (65\%) marijuana, 54 $(87 \%)$ crack and 57 (92\%) heroin. 26 clients (42\%) injected heroin. Only 17 (24\%) reported having had spirometry. Clients were divided into tertiles ('heavy', 'moderate' and 'mild' exposure to smoked tobacco and drugs) according to total smoking history (combined pack years, joints/day years, rocks/day years and bags/ day years respectively for tobacco, marijuana, crack and heroin). There were no statistically significant differences between groups - See Table 1.

Conclusions The majority of the clients reported at least one symptom suggestive of airways disease. A larger study incorporating spirometry based at drug clinics may haelp to diagnose, and thereby facilitate effective treatment, of underlying COPD in this population. Early diagnosis and treatment could reduce illness within this population, prevent admissions and lead to significant savings in NHS spending.

\section{REFERENCES}

1. United Nations Office on Drugs and Crime, World Drugs report 2012

2. Pulmonary effects of illicit drug use, Clin Chest Med. 2004 Mar;25(1):203-16, Wolff AJ et al.

5. Scoring System and Clinical Application of COPD Diagnostic Questionnaires, CHEST. June 2006;129(6):1531-1539. doi:10.1378/chest.129.6.1531, Price DB et al.

\begin{tabular}{llll} 
Abstract P126 Table 1. & & & \\
\hline & Heavy & Moderate & Mild \\
\hline Number & 21 & 21 & 20 \\
Mean MRC score - good day & 2.00 & 1.81 & 2.30 \\
Mean MRC score - bad day & 2.85 & 2.43 & 2.60 \\
Kept indoors with chest symptoms (\%) & 33.33 & 47.62 & 45.00 \\
Cough (\%) & 42.86 & 66.67 & 55.00 \\
Admitted to hospital with chest problems (\%) & 38.10 & 28.57 & 25.00 \\
Ever had inhalers (\%) & 57.14 & 61.90 & 50.00 \\
COPD/Emphysema/Bronchitis (\%) & 33.33 & 23.81 & 30.00 \\
Asthma (\%) & 47.62 & 42.86 & 40.00 \\
\hline
\end{tabular}

\section{P127 RADIOLOGICAL DIAGNOSIS OF EMPHYSEMA, PNEUMOTHORAX AND BULLAE: CASE FOR TOBACCO AND CANNABIS SMOKING HISTORIES}

B Selvarajah, R Colliver, C Cleland, P Beddoes, S Howling, Ш Restrick, M Stern; Whittington Health, London, UK

\subsection{6/thoraxjnl-2013-204457.277}

Introduction There is increasing evidence that cannabis smoking, combined with tobacco, increases the risk of emphysema and bullous lung disease (BLF Report 2012). The aim of this retrospective case study was to determine the prevalence of tobacco and/or cannabis smoking amongst patients $<50$ years with radiologically-diagnosed emphysema, pneumothorax or bullous lung disease, and to assess the quality of smoking documentation.

Methods A list of all high-resolution computerised tomography (HRCT) scans over 2 years (Jan2010-Dec2012), of patients $\leq 50$ years at scan date was generated from the radiology database. All scans were reviewed by a Consultant Thoracic Radiologist to confirm accuracy of initial reports. Case notes of all patients with radiological emphysema, pneumothorax or bullous lung disease were reviewed for tobacco and cannabis smoking histories to examine the relationship with abnormalities.

Results 361 HRCTs were performed over 2 years in $\leq 50$ year olds. 91/361 (25.2\%) scans were reported as emphysema, pneumothorax or bullae. $85 / 91$ notes were available for analysis and $62 / 85(73 \%)$ had full smoking histories recorded; 7/85(8.2\%) tobacco smoking history not recorded and 22/85(25.9\%) cannabis smoking history not recorded. $27 / 48$ (56\%) current tobacco smokers with an abnormal HRCT also smoke cannabis. There 
were no cannabis-only smokers and only 6/62 (9.7\%) were never-smokers (tobacco\&cannabis).

$56 / 62(90 \%)$ abnormal HRCTs were in ex/current tobacco smokers and $27 / 62(44 \%)$ were in current tobacco\&cannabis smokers. There was a higher prevalence of pneumothoraces and bullae with a cannabis and tobacco smoking history than for tobacco alone but this was not statistically significant different (chi-squared STATA) (Table1).

Conclusion More than half of tobacco smokers with abnormal HRCTs also had a history of previous and current cannabis smoking. Despite these findings $25 \%$ of patients with abnormal HRCTs had no documentation regarding cannabis smoking. This population of $\leq 50$ years olds with abnormal HRCTs did not smoke cannabis without tobacco. While not statistically significant, bullae and pneumothoraces were more frequently observed in patients who smoked tobacco with cannabis compared to tobacco alone. Larger studies are needed to further understand the additive effect of cannabis smoking to tobacco-induced lung damage. These studies will require systematic recording of both tobacco and cannabis smoking histories.

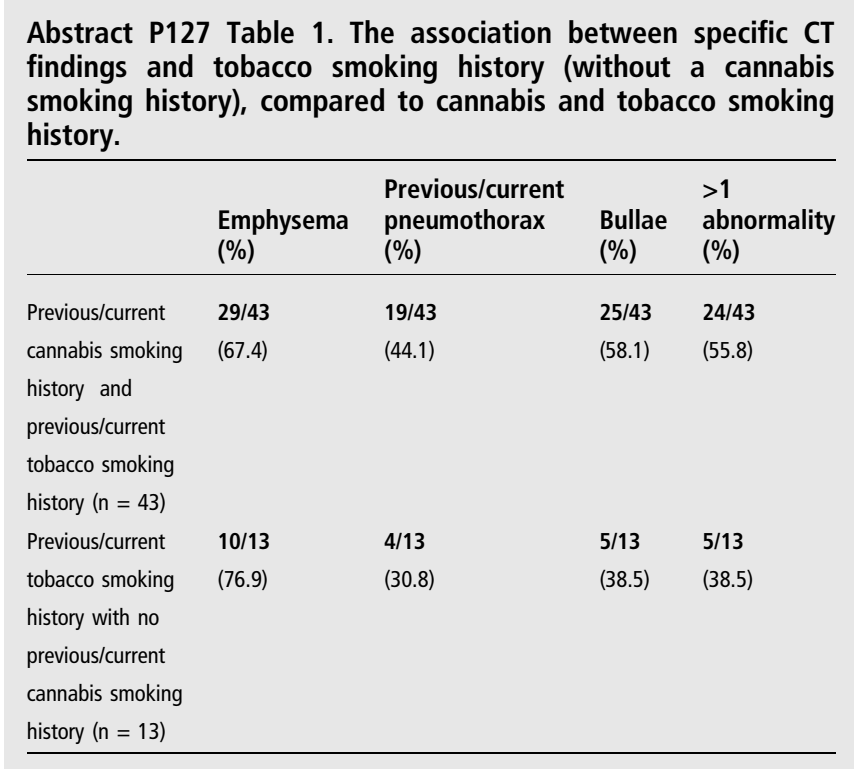

\section{COPD exacerbations: the heart of the matter}

\section{P128 CARDIOVASCULAR EFFECTS OF STATIN THERAPY ON ARTERIAL STIFFNESS IN PATIENTS WITH COPD: A DOUBLE BLIND RANDOMISED CONTROLLED TRIAL}

${ }^{1} \mathrm{M}$ John, ${ }^{2} \mathrm{JR}$ Cockcroft, ${ }^{3} \mathrm{TM}$ McKeever, ${ }^{1} \mathrm{TW}$ Harrison, ${ }^{2} \mathrm{DJ}$ Shale, ${ }^{4} \mathrm{JG}$ Thornton, ${ }^{1} \mathrm{AJ}$ Knox, ${ }^{1}$ CE Bolton; 'Nottingham Respiratory Research Unit, Nottingham, UK; ${ }^{2}$ Wales Heart Research Institute, Cardiff, UK; ${ }^{3}$ School of Community Health Sciences, Nottingham, UK; ${ }^{4}$ Nottingham Clinical Trials Unit, Nottingham, UK

\subsection{6/thoraxjnl-2013-204457.278}

Background As cardiovascular disease is a comorbidity and major cause of death in patients with COPD, primary preventative strategies are required. Arterial stiffness, as measured by aortic pulse wave velocity (PWV) is increased in patients with $\mathrm{COPD}^{1}$, and is an independent predictor of cardiovascular risk ${ }^{2}$, which is modifiable over the short term. We hypothesised that aortic PWV, would be reduced by six weeks treatment of simvastatin $20 \mathrm{mg}$ once daily compared to placebo in selected patients with COPD without concurrent heart disease, diabetes or hypercholesterolemia.

Methods Clinically stable patients with confirmed COPD were recruited and randomised to either simvastatin $20 \mathrm{mg}$ od (active) or placebo in double blinded fashion. Aortic PWV, blood pressure, spirometry, six minute walking distance, and lipids were measured pre- and post- 6 weeks treatment. Primary analysis compared PWV between groups. A predefined subgroup analysis compared those with a baseline PWV $\geq 10 \mathrm{~m} / \mathrm{s}$.

Results The patients were well matched for age, sex, smoking and lung function; active, $\mathrm{n}=33$ and placebo, $\mathrm{n}=37$. The recruitment target was met. Compliance was high with the active group achieving significantly lower total cholesterol - between arms mean (95\% CI): $-1.1(-1.3,-0.8) \mathrm{mmol} / \mathrm{L}, \mathrm{p}<0.001$. There was no significant change in aortic PWV after treatment in the active compared to placebo group: $-0.7(-1.8,0.5) \mathrm{m} / \mathrm{s}, \mathrm{p}=0.24$, In the subgroup with aortic PWV $\geq 10 \mathrm{~m} / \mathrm{s}, \mathrm{n}=22$, aortic PWV improved in the active arm compared to placebo: $-2.8(-5.2$, $-0.3) \mathrm{m} / \mathrm{s}, \mathrm{p}=0.03$. This latter difference remained statistically significant after adjusting for age and sex. Blood pressure, lung function and six minute walking distance did not change.

Conclusions In this pilot study, despite a significant reduction in total cholesterol there was no improvement in aortic PWV in patients with COPD taking simvastatin $20 \mathrm{mg}$ compared to placebo over 6 weeks. The positive findings in the subgroup with a higher baseline aortic PWV warrants further studies in high risk patients to confirm the impact of statin use on the cardiovascular outcome of COPD.

Trial reference: NCT01151306

Supported by NIHR RfPB grant

\section{REFERENCES}

1. Sabit, R., et al., Am J Respir Crit Care Med, 200;175:1259-65

2. Laurent, S., et al., Eur Heart J, 2006; 27:2588-605

\section{P129 SKELETAL MUSCLE WEAKNESS, NOT ARTERIAL STIFFNESS, DIFFERS ACCORDING TO GOLD GROUP IN COPD}

${ }^{1} \mathrm{M}$ Fisk, ${ }^{2} \mathrm{~N}$ Gale, ${ }^{3} \mathrm{D}$ Mohan, ${ }^{4} \mathrm{MN}$ Marchong, ${ }^{4} \mathrm{~J}$ Forman, ${ }^{5} \mathrm{DA}$ Lomas, ${ }^{2} \mathrm{JR}$ Cockcroft, ${ }^{6} \mathrm{CE}$ Bolton, ${ }^{7} \mathrm{~W}$ MacNee, ${ }^{4} \mathrm{~J}$ Fuld, ${ }^{8} \mathrm{CM}$ Calverley, ${ }^{1} \mathrm{CM}$ McEniery, ${ }^{9} \mathrm{R}$ Tal-Singer, ${ }^{1}$ IB Wilkinson, ${ }^{3}$ MI Polkey; ${ }^{1}$ University of Cambridge \& Cambridge University Hospitals NHS Foundation Trust, Cambridge, UK; ${ }^{2}$ Wales Heart Research Institute, Cardiff, UK; ${ }^{3}$ Royal Brompton \& Harefield NHS Foundation Trust, London, UK; ${ }^{4}$ Cambridge University Hospitals NHS Foundation Trust, Cambridge, UK; ${ }^{5}$ University College London \& Royal Free Hospital NHS Foundation Trust, London, UK; ${ }^{6}$ Nottingham Respiratory Research Unit, University of Nottingham, Nottingham, UK; ' ${ }^{7}$ Edinburgh University, Edinburgh, UK; ${ }^{8}$ University of Liverpool, Liverpool, UK; ${ }^{9}$ GlaxoSmithKline, King of Prussia, USA

\subsection{6/thoraxjn-2013-204457.279}

Introduction In the GOLD 2011 COPD classification, patients in Group D are considered to be at highest risk of mortality, due to airflow limitation and exacerbations and also to be most symptomatic. Skeletal muscle weakness and cardiovascular disease are associated with mortality in patients with COPD and elderly people per se. We hypothesised that GOLD D patients would have more severe extra-pulmonary manifestations of COPD than A-C.

Objectives To measure skeletal muscle weakness and arterial stiffness (an independent predictor of cardiovascular risk) in the ERICA (Evaluating the Role of Inflammation in Chronic Airways 